\title{
Allometric Growth of Sargassum fusiforme (Ochrophyta, Fucales) Organs in the Maturation Period Based on Biomass Analysis of Samples from Gouqi Island
}

\author{
Xunmeng Li ${ }^{1,2, \dagger}$, Kai Wang ${ }^{1,2, *}$, Jianqu Chen ${ }^{1,2,+}$ and Shouyu Zhang $1,2, *$ \\ 1 College of Marine Ecology and Environment, Shanghai Ocean University, Shanghai 201306, China; \\ d180400069@st.shou.edu.cn (X.L.); m190400972@st.shou.edu.cn (J.C.) \\ 2 Engineering Technology Research Center of Marine Ranching, Shanghai Ocean University, \\ Shanghai 201306, China \\ * Correspondence: kwang@shou.edu.cn (K.W.); syzhang@shou.edu.cn (S.Z.); Tel.: +86-21-6190-0336 (S.Z.) \\ + These authors contributed to the work equally and should be regarded as co-first authors.
}

Citation: Li, X.; Wang, K.; Chen, J.; Zhang, S. Allometric Growth of Sargassum fusiforme (Ochrophyta, Fucales) Organs in the Maturation Period Based on Biomass Analysis of Samples from Gouqi Island. J. Mar. Sci. Eng. 2021, 9, 1320. https:// doi.org/10.3390/jmse9121320

Received: 10 October 2021

Accepted: 19 November 2021

Published: 23 November 2021

Publisher's Note: MDPI stays neutral with regard to jurisdictional claims in published maps and institutional affiliations.

Copyright: (c) 2021 by the authors. Licensee MDPI, Basel, Switzerland. This article is an open access article distributed under the terms and conditions of the Creative Commons Attribution (CC BY) license (https:// creativecommons.org/licenses/by/ $4.0 /)$.

\begin{abstract}
Sargassum fusiforme is a seaweed species that plays an important role in the diverse communities of the flora and fauna of coastal food webs. Assessments of its biomass and energy allocation in addition to allometric organ growth have important ecological value for understanding the community structure, carbon storage, and resource assessment of seaweed beds during periods in which they thrive. In this study, the morphology of Sargassum fusiforme and the biomass of organs and total organisms in the maturation period were studied, and the allometric relationships for different organs of Sargassum fusiforme were analyzed using the standardized major axis (SMA). In the maturation period of Sargassum fusiforme, branch number, height $\times$ stem diameter were the prior independent variables, and the optimum biomass was $y=0.002 x^{1.107}\left(R^{2}=0.923\right)$. The biomass allocation ratio of blades was the highest (38.33\%), followed by stems $(32.90 \%)$ and receptacles $(28.77 \%)$. The growth rates of the various organs were found to differ, and the rate of biomass increase for the blades and stems tended to converge. The rate of receptacle biomass growth of Sargassum fusiforme was the highest in the maturation period, and the rate of organ biomass increase was $W_{\mathrm{b}}<W_{\mathrm{s}}<W_{\mathrm{t}}<W_{\mathrm{r}}$, which reflects the trade-off with energy allocation as a strategy used by Sargassum fusiforme.
\end{abstract}

Keywords: intertidal zone; biomass; allometric growth; Sargassum fusiforme; maturation period

\section{Introduction}

Seaweed is one of the primary producers in coastal marine ecosystems and is responsible for maintaining material circulation and energy flow [1]. It is also a blue (marine) carbon sink and performs irreplaceable functions in fishery resources conservation and water purification [2]. The biomass during maturation periods is one of the basic biological parameters of seaweed, which represents the accumulation of material and energy in the organism [3]. The assessment of a coastal zone's blue carbon sequestration potential is based on the evaluation of its seaweed resources in the maturation period, and the assessment of seaweed resources, in turn, is based on the organism biomass. Traditional seaweed biomass surveys have been carried out mainly by quadrat and transect analysis, but the required sample collection is time-consuming and often hindered by strong wind and waves, which cause serious ecological damage, especially to endangered species [4,5]. In addition, because of the narrow horizontal distribution of seaweed in the intertidal zone and the great effect of waves, it is difficult to determine its biomass from satellite images. In recent years, unmanned aerial vehicles (UAVs) equipped with multispectral cameras have been widely used in coastal ecological surveys because they provide wide coverage and flexible operation [6,7]. By using the morphological characteristics of the target, the 
biomass can be indirectly realized at close range through inversion [8,9]. Therefore, it is a quick and convenient method for constructing and assessing the morphological features (height, stem diameter, branch number, crown width) and total biomass of seaweed in the maturation period.

To adapt to local growing conditions, seaweed needs to adequately adjust its mechanisms to promote growth and reproduction [10]. The allometric growth relationship refers to the quantitative expression of growth and energy distribution of different organs within an individual and is affected by a variety of external factors, such as light intensity and water temperature, with different population characteristics [11]. Understanding the biomass allocation and allometric growth strategies among different organs of seaweed is the basis for understanding internal energy supply, carbon cycle, and energy storage in seaweed during the maturation period.

Different organs have different biomasses [12], and the accuracy of assessment based on multiple factors is often better than that of a single variable $[13,14]$. Until now, studies of biomass and allometric organ growth have been conducted on woody plants and herbs but have rarely been reported for seaweed [15-18]. Seaweed have not been examined to determine whether the partitioning of their body parts into 'leaf', 'stem', and 'root' analogs accords with spermatophytes [19]. Weight/length allometry of seaweed is highly variable, both seasonally and between years [20]. Although the best descriptive biometric variable varies according to seaweed morphology, Stagnol found that the power equation was the best model for predicting seaweed biomass [21].

Sargassum fusiforme is a perennial warm temperate seaweed species in the Northwest Pacific Ocean. It is one of the main species of economic importance in China, widely distributed in the coastal waters of Liaoning, Zhejiang, Fujian, and Guangdong provinces, among which they are most abundant in Zhejiang [22]. Although Ruan and Zhang studied the reproductive biology and life cycle of Sargassum fusiforme, they did not explore its internal growth adaptability $[23,24]$. Furthermore, there are no documented statistics on naturally occurring Sargassum fusiforme resources in China. This study examines Sargassum fusiforme, the dominant seaweed species in the intertidal zone of Gouqi Island in Zhejiang Province, to characterize the biomass characteristics of its organs in the maturation period according to seaweed morphological features and determine the allometric growth law of organ biomass for this species. The aim is to provide theoretical data for the assessment of its resources and carbon sequestration ability.

\section{Materials and Methods}

\subsection{Study Area}

The study area was located in the intertidal zone of Gouqi Island, Zhejiang Province $\left(122^{\circ} 44^{\prime} 08^{\prime \prime}-122^{\circ} 47^{\prime} 37^{\prime \prime} \mathrm{E} ; 30^{\circ} 41^{\prime} 49^{\prime \prime}-30^{\circ} 44^{\prime} 02^{\prime \prime} \mathrm{N}\right)$. This area has a subtropical monsoon climate, with an average annual water temperature of $17-19{ }^{\circ} \mathrm{C}$ [25]. The intertidal zone bottom is mainly composed of reef and rich in seaweeds, including Sargassum fusiforme, Sargassum thunbergii, and Ulva pertusa. The seedlings of Sargassum thunbergii start growing in the autumn and flourish the following summer [26].

\subsection{Materials}

Sargassum fusiforme (class: Phaeophyceae; family: Sargassaceae; genus: Sargassum), grows on reefs in the low intertidal zone, where it is often exposed to waves. It has a tawny color and a length of 40-100 cm. The organism is composed of a holdfast, stem, receptacles, blades, and a pneumatocyst. The top of a blade often expands and turns into a pneumatocyst, and receptacles grow from the blades [27].

\subsection{Methods}

The study site, which was scarcely affected by human activity, was selected for the collection of Sargassum fusiforme samples using a random sampling strategy. The collection date was 20 July 2020, when Sargassum fusiforme was fully mature, and the biomass was 
stable and at its annual maximum. The longitude and latitude of the $30 \times 30 \mathrm{~cm}$ random sampling plot was recorded according to the global positioning system (GPS), and samples were then cut from the reefs, using a small shovel to maintain the integrity of the fronds as much as possible, and preserved in seawater containing $7 \%$ formaldehyde.

In the laboratory, the seaweed was wiped with a brush to remove sand and sediment before determining its biological parameters [28]. The height $(\mathrm{H}, \mathrm{cm})$, fresh weight $(\mathrm{W}, \mathrm{g})$, stem diameter $(\mathrm{SD}, \mathrm{cm})$, branch number $(\mathrm{BN})$, and crown width $(\mathrm{D}, \mathrm{cm})$ were measured for each sample. The blades, stems, and receptacles were dissected using tweezers, classified, numbered, and placed into an oven for drying at $100{ }^{\circ} \mathrm{C}$ for $24 \mathrm{~h}$ to a constant weight [29]. The blades were clavate, and the tops were often inflated and changed into pneumatocysts [27]. As the mechanism of distinguishing blade and pneumatocyst is still unclear, what is taken and referred to as the blade biomass in this study also includes the pneumatocyst. The biomass of blades $(\mathrm{Wb}, \mathrm{g})$, receptacles $(\mathrm{Wr}, \mathrm{g})$, stems $(\mathrm{Ws}, \mathrm{g})$, and the total biomass $(\mathrm{Wt}, \mathrm{g})$ were determined.

\subsection{Statistical Analysis}

The data were analyzed using SPSS 20.0 (SPSS, Chicago, IL, USA) and Origin 8.0 (Origin, Originlab, Northampton, MA, USA). Morphological features such as height $(\mathrm{H})$, stem diameter $(\mathrm{SD})$, branch number $(\mathrm{BN})$, crown width $(\mathrm{D})$, and combined variables such as height $\times$ crown width (HD), height $\times$ stem diameter (HSD), height $\times$ stem diameter $\times$ stem diameter $\left(\mathrm{HD}^{2}\right)$, and crown width $\times$ branch number $(\mathrm{DBN})$ were selected to establish the mathematical relationships of organs and total biomass. Five relationships were used to explore the optimum biomass relationship of Sargassum fusiforme [14]:

$$
\begin{gathered}
W=a+b X \\
W=a+b X+c X^{2} \\
W=a+b X+c X^{2}+d X^{3} \\
W=a e^{b X} \\
W=a X^{b}
\end{gathered}
$$

where $W$ is the biomass of different organs, and $X$ is morphological features or combined variables.

Eighty percent of the samples were randomly selected as the basis for building the biomass relationship for which height, branch number, stem diameter, crown width, height $\times$ stem diameter, height $\times$ crown width, and crown width $\times$ branch number were selected as independent variables. Blade, stem, receptacle, and total biomass were dependent variables. The mathematical relationship was constructed using the above five formulas one by one. To verify the reliability of the relationship properties, the data of the remaining $20 \%$ of the samples were used to validate the determined relationships, and the accuracy of the results was assessed by analysis of the mean absolute error (MAE) (6) and root mean square error (RMSE) (7) [30]:

$$
\begin{gathered}
M A E=\frac{1}{n} \sum_{i=1}^{n}\left|w_{i}^{\prime}-w_{i}\right| \\
R M S E=\sqrt{\frac{1}{n} \sum_{i=1}^{n}\left(w_{i}-w_{i}^{\prime}\right)^{2}}
\end{gathered}
$$

where $w_{i}$ is the real value of the seaweed organs or total biomass, and $w_{i}^{\prime}$ is the predicted value. The optimum biomass relationship of Sargassum fusiforme was selected according to a comprehensive analysis of the coefficient of determination $\left(\mathrm{R}^{2}\right)$, F-test, $p$ value $(p<0.001)$, MAE, and RMSE [31]. The standard major axis (SMA) was used to establish the allometric growth equation, and SMART 2.0 was used to calculate the parameters [32,33]. Allometric 
growth is often expressed as a power function showing the relationship among morphological, organic, and individual biomass [34]. In the calculation of the allometric growth equation, a logarithmic transformation of the power function was needed:

$$
Y=a X^{b}
$$

and after logarithmic transformation,

$$
\log Y=\log a+b \log X
$$

where $X$ and $Y$ are the organ and total biomass, respectively; $a$ and $b$ are constants; log $a$ is the intercept of the equation; and $b$ stands is the slope (allometric growth index). When $|b|=1.0, X$ and $Y$ grew at the same rate; otherwise, they were considered to have an allometric growth relationship. Meanwhile, the significance $\left(P_{1.0}\right)$ was judged by the difference between the slope and the theoretical value of 1.0 [33].

\section{Results and Analysis}

\subsection{Biological Characteristics Sargassum fusiforme}

The morphological parameters and organ biomasses changed greatly (Table 1). In the maturation period, the average height of Sargassum fusiforme was $42.00 \pm 16.98 \mathrm{~cm}$, and the average wet weight was $7.94 \pm 5.29 \mathrm{~g}$. There was great variation in the branch number of seaweed (9-64), and the average total biomass (dry weight) was $0.88 \pm 0.58 \mathrm{~g}$. The biomass of all the organs was lowest for the receptacles $(0.31 \pm 0.29 \mathrm{~g})$, accounting for $28.77 \%$ of the total biomass, and the highest for blades $(0.3 \pm 0.18 \mathrm{~g})$.

Table 1. Biological parameters of Sargassum fusiforme.

\begin{tabular}{ccccc}
\hline Variable & & Max & Min & Mean \pm SD \\
\hline Height & $H(\mathrm{~cm})$ & 68.50 & 7.00 & $42.00 \pm 16.98$ \\
Fresh Weight & $W(\mathrm{~g})$ & 20.56 & 0.64 & $7.94 \pm 5.29$ \\
Branch Number & $B N$ & 64.00 & 9.00 & $34.40 \pm 13.41$ \\
Stem Diameter & $S D(\mathrm{~cm})$ & 0.25 & 0.13 & 0.1850 .03 \\
Crown Width & $D(\mathrm{~cm})$ & 8.20 & 2.80 & $5.11 \pm 1.64$ \\
Height $\times$ Stem Diameter & $H S D\left(\mathrm{~cm}^{2}\right)$ & 13.65 & 1.32 & $7.56 \pm 3.35$ \\
Height $\times$ Crown Width & $H D\left(\mathrm{~cm}^{2}\right)$ & 536.28 & 28.00 & $230.70 \pm 146.87$ \\
Crown Width $\times$ Branches & $D B N$ & 444.00 & 31.50 & $185.80 \pm 115.30$ \\
Blades Biomass & $W_{b}(\mathrm{~g})$ & 0.73 & 0.04 & $0.30 \pm 0.18$ \\
Receptacles Biomass & $W_{r}(\mathrm{~g})$ & 1.03 & 0.003 & $0.31 \pm 0.29$ \\
Stems Biomass & $W_{s}(\mathrm{~g})$ & 0.61 & 0.03 & $0.26 \pm 0.14$ \\
Total Biomass & $W_{t}(\mathrm{~g})$ & 2.34 & 0.09 & $0.88 \pm 0.58$ \\
Blades Biomass (Percentage & $(\%)$ & 66.97 & 19.49 & $38.33 \pm 10.29$ \\
$\quad$ of Total) & & & & \\
Receptacles Biomass & $(\%)$ & 50.09 & 3.37 & $28.77 \pm 13.13$ \\
(Percentage of Total) & & & & \\
Stems Biomass (Percentage & $(\%)$ & 47.19 & 21.43 & $32.90 \pm 7.72$ \\
of Total) & & & & \\
\hline
\end{tabular}

\subsection{Optimal Biomass Relationship in Maturation Period of Sargassum fusiforme}

In fitting the relationship between organs and total biomass, the power function was optimal and presented a significant relationship $(p<0.001)$ (Table 2). However, the correlation of the organ biomasses with the independent variables differed, as did the morphological factors constituting the relationship, mainly the branch number (BN) and height $\times$ stem diameter (HSD). 
Table 2. Optimum biomass relationships of Sargassum fusiforme.

\begin{tabular}{|c|c|c|c|c|c|c|c|c|}
\hline \multirow{2}{*}{ Organs } & \multirow{2}{*}{ Relationships } & \multirow{2}{*}{$R^{2}$} & \multirow{2}{*}{$F$} & \multirow{2}{*}{$p$} & \multicolumn{2}{|c|}{ Coefficient } & \multirow{2}{*}{ MAE } & \multirow{2}{*}{ RMSE } \\
\hline & & & & & $a$ & $b$ & & \\
\hline$W_{b}$ & $W=\mathrm{a}(B N)^{\mathrm{b}}$ & 0.774 & 95.984 & $<0.001$ & 0.003 & 1.286 & 0.074 & 0.095 \\
\hline$W_{r}$ & $W=\mathrm{a}(B N)^{\mathrm{b}}$ & 0.937 & 413.166 & $<0.001$ & $5.332 \times 10^{-6}$ & 3.003 & 0.075 & 0.109 \\
\hline$W_{S}$ & $W=\mathrm{a}(H S D)^{\mathrm{b}}$ & 0.910 & 284.480 & $<0.001$ & 0.025 & 1.146 & 0.034 & 0.055 \\
\hline$W_{t}$ & $W=\mathrm{a}(B N)^{\mathrm{b}}$ & 0.923 & 334.320 & $<0.001$ & 0.002 & 1.707 & 0.015 & 0.189 \\
\hline
\end{tabular}

$W_{b}$ is blade biomass; $W_{r}$ is receptacle biomass; $W_{s}$ is stem biomass; $W_{t}$ is total biomass; $B N$ is branch number; $H S D$ is height $\times$ stem diameter.

Figure 1 shows the optimum biomass relationship of each organ and the total Sargassum fusiforme biomass. It can be seen that the optimum relationship between blade, receptacle, and total biomass were power functions, which increased with the branch number $(\mathrm{BN})$ as an independent variable. Among them, the regression coefficients of the optimum relationship of receptacle biomass had the highest value $\left(R^{2}=0.937, p<0.001\right)$. The optimum biomass relationship of stems was based on height $\times$ stem diameter (HSD) and presented a power function equation with independent variables. The stems biomass increased with height $\times$ stem diameter $(\mathrm{HSD})\left(R^{2}=0.910, p<0.001\right)$.
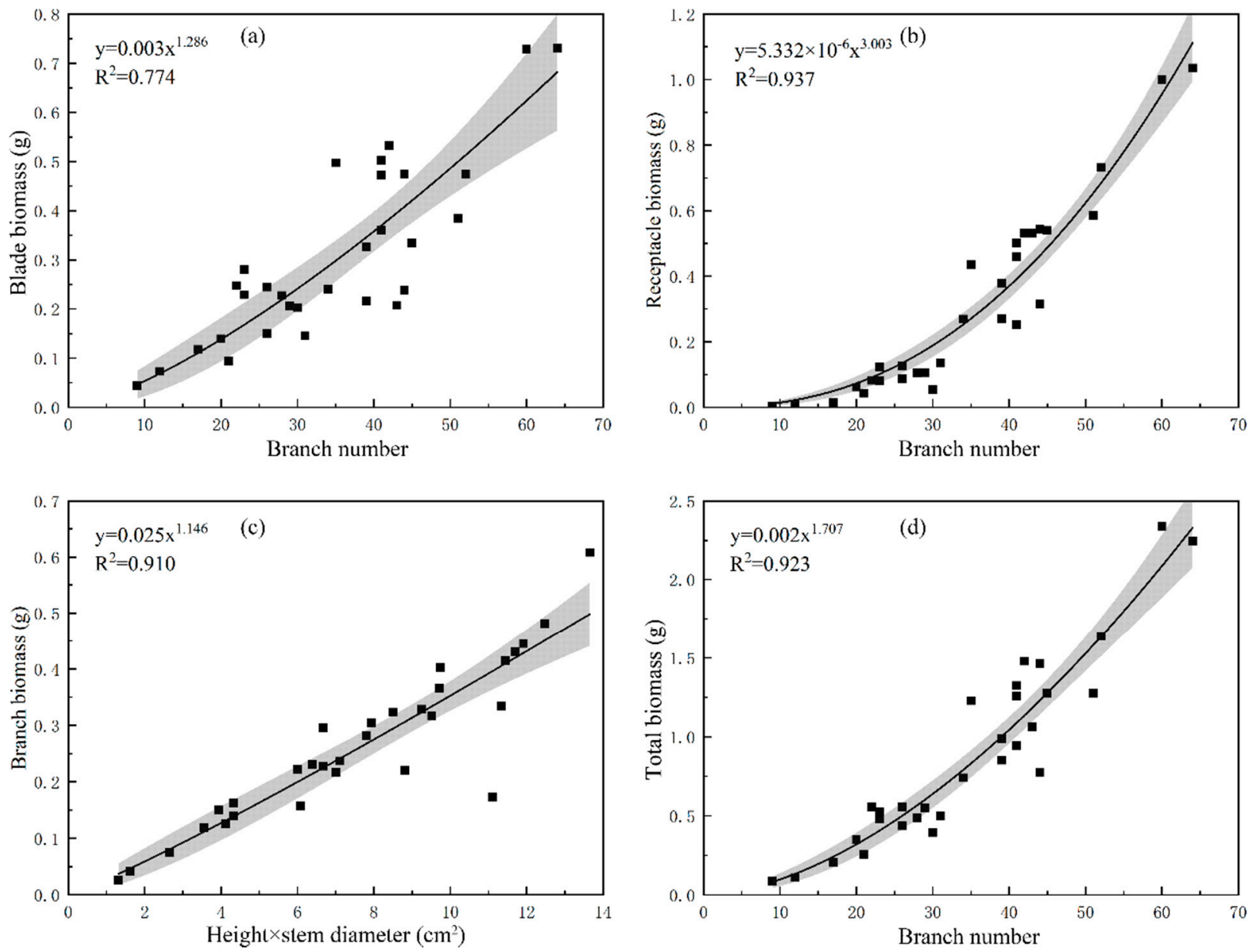

Figure 1. Optimum biomass relationships of Sargassum fusiforme. The black line is the fit curve, and the gray area is the $95 \%$ confidence region. (a-d) are the optimum biomass relationships of different organs.

\subsection{Allometric Growth of Organs in the Maturation Period of Sargassum fusiforme}

There were some differences in the allocation biomass among different organs, and there was a positive correlation of blade, receptacle, stem, and total biomass (Table 3). The standardized major axis (SMA) analysis showed that the organ biomasses and the 
total biomass were in an allometric growth relationship, and the fitting equations were significant $(p<0.001)$. However, there was no significant difference between the SMA slope and the theoretical value of 1.0 for blade-stem biomass, indicating that they tended to grow at a similar rate.

Table 3. SMA analysis results of organs and total biomass of Sargassum fusiforme.

\begin{tabular}{cccccccc}
\hline Variable & $\boldsymbol{R}^{\mathbf{2}}$ & $\boldsymbol{p}$ & Slope & $\begin{array}{c}\mathbf{9 5 \%} \text { Slope } \\
\text { Confidence } \\
\text { Interval }\end{array}$ & Intercept & $\begin{array}{c}\text { 95\% Intercept } \\
\text { Confidence Interval }\end{array}$ & $\boldsymbol{P}_{\mathbf{1 . 0}}$ \\
\hline$W_{b}-W_{r}$ & 0.820 & $<0.001$ & 0.471 & $0.400-0.555$ & -0.234 & -0.310 to -0.158 & $<0.001$ \\
$W_{b}-W_{s}$ & 0.766 & $<0.001$ & 0.942 & $0.782-1.135$ & 0.025 & -0.104 to 0.153 & 0.517 \\
$W_{s}-W_{r}$ & 0.876 & $<0.001$ & 0.500 & $0.437-0.573$ & -0.275 & -0.341 to -0.208 & $<0.001$ \\
$W_{b}-W_{t}$ & 0.909 & $<0.001$ & 0.823 & $0.733-0.924$ & -0.461 & -0.497 to -0.424 & 0.002 \\
$W_{t}-W_{r}$ & 0.963 & $<0.001$ & 0.573 & $0.532-0.617$ & 0.276 & 0.234 to 0.317 & $<0.001$ \\
$W_{s}-W_{t}$ & 0.923 & $<0.001$ & 0.874 & $0.785-0.973$ & -0.516 & -0.551 to -0.480 & 0.016 \\
\hline
\end{tabular}

The allometric growth indices of the blade-receptacle, stem-receptacle, and totalreceptacle biomass were significantly different from the theoretical value of $1.0(p<0.001)$ The allometric growth index value for each was less than 1.0, indicating that the increase rate of blades biomass was less than that of the stems, the increase rate of stems biomass was less than that of the total, and the increase rate of the total biomass was less than that of receptacles (Figure 2). Among them, the difference between the blade and receptacle biomass was the highest, and the allometric growth index was 0.47 .
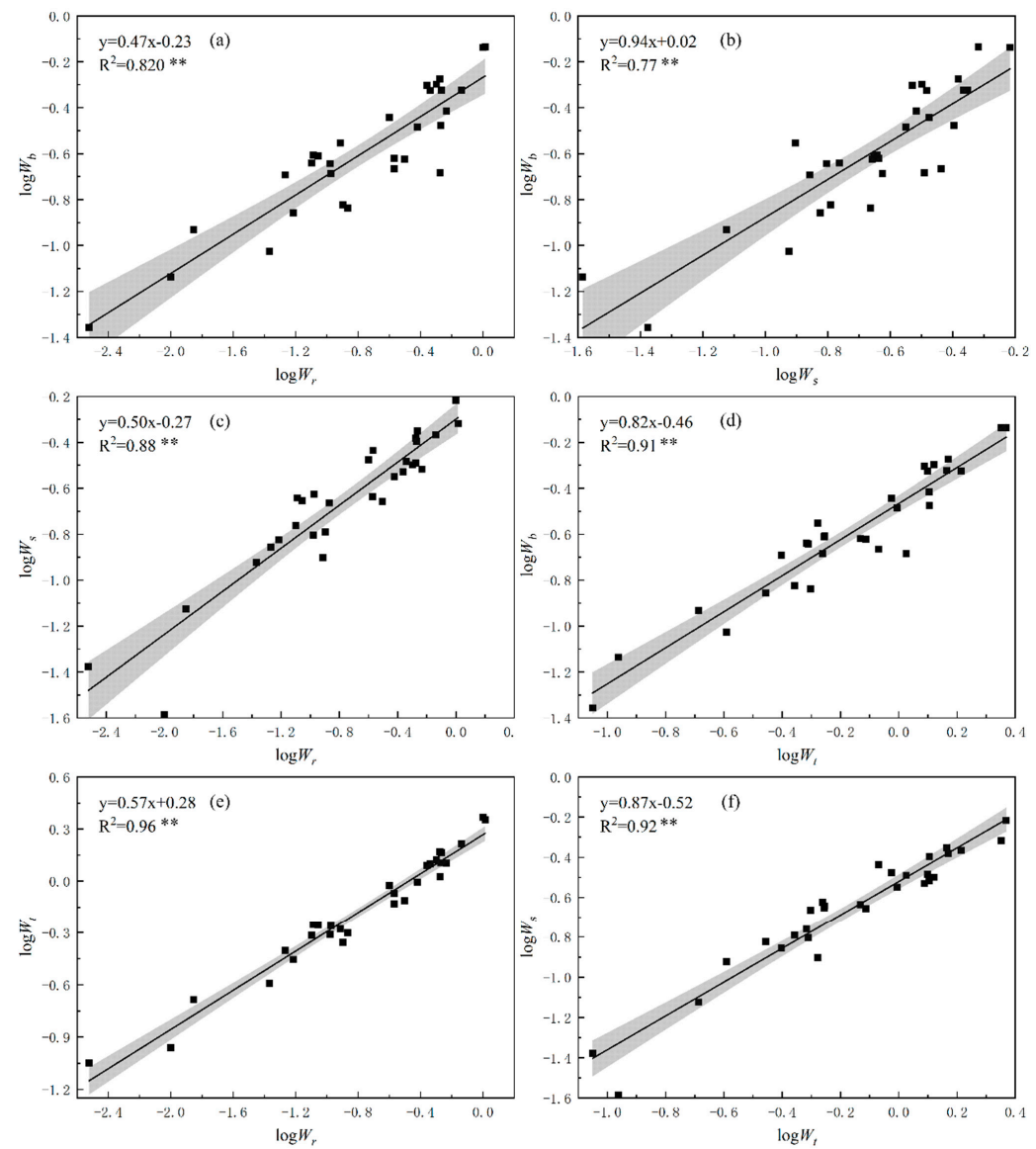

Figure 2. Allometric growth relationship of different organs of Sargassum fusiforme. The black line is the fit curve; the gray area is the $95 \%$ confidence region. ${ }^{* *}$ significant correlation $(p<0.01),(\mathbf{a}-\mathbf{f})$ are the optimum biomass relationships of different organs. 


\section{Discussion}

\subsection{Optimal Biomass Relationships of Sargassum fusiforme}

For the selection of seaweed biomass relationships, the equation with simple structure and easy measurement of independent variables should be selected on the premise of prediction accuracy. Furthermore, the prediction effect of compositional variables was often better than that of single variables. Therefore, when selecting a biomass relationship, each variable should be comprehensively analyzed [35]. In this study, the best independent variable for determining Sargassum fusiforme stem biomass was the combined variable height $\times$ stem diameter (HSD), with the highest coefficient of determination value $\left(R^{2}=0.91, p<0.001\right)$, which was the same as the combined variables selected in the optimum relationship of Eucommia ulmoides stem biomass by Ma Shunxing [36]. Although Sargassum fusiforme is similar in appearance to terrestrial plants, height $\times$ stems diameter $\times$ stem diameter $\left(\mathrm{HD}^{2}\right)$ is often the best independent variable for prediction in trees and shrubs, based on its optimum biomass [37], while for Sargassum fusiforme, the branch number $(\mathrm{BN})$ was found to be the best independent variable for prediction $\left(\mathrm{R}^{2}=0.92, p<0.001\right)$, which was better than the fitting result of $\mathrm{HD}^{2}\left(R^{2}=0.84, p<0.001\right)$. This also fully reflects the difference in physiology between seaweed and terrestrial plants. Environmental factors affect the biomass distribution of plant components, grazing and herbivores increased the distribution of root biomass and decreased the proportion of stem and leaf biomass [38]. The holdfast of Sargassum fusiforme only plays the role of fixing, with less biomass, and seaweed often grow in the intertidal zone of rocky reefs without human activities and were rarely eaten by hydrobios such as Caprellidae and Siganidae [39]. Although Sargassum fusiforme often grows close to Sargassum thunbergii, under the movement of waves, Sargassum thunbergii covers the surface of Sargassum fusiforme occasionally, but it will not have a great impact on the photosynthesis of Sargassum fusiforme under frequent current scouring [40].

Besides the blades, receptacles, and stems, seaweed also have a holdfast that is used for fixation. Similar to other annuals, seaweed usually allocates more energy to aboveground components [41], but unlike terrestrial plants, the function of the holdfast of Sargassum fusiforme is to attach the seaweed to a rock surface, and its biomass is much lower than that of other organs, and seaweed also exhibits tip growth. The main organs of nutrient absorption are the blades and stems, and the contribution of the holdfast was lower [41]. When the seaweed holdfast was collected, a large number of impurities adhered, namely sand and sediment. These were very difficult to remove and made it difficult to maintain the integrity of the holdfast. Therefore, it was not considered in the construction of the Sargassum fusiforme biomass relationship.

\subsection{Allometric Growth Relationship among Different Organs}

Biological organisms increase their adaptation to factors in the external environment (such as light and nutrients) through the phenotypic plasticity of their own features toward an improved self-protection mechanism and allowing maintained progression of the life cycle [42]. Allometric growth of biomass is a basic aspect of genotype strategy and the result of natural selection [43]. During the self-development of Sargassum fusiforme, the success of the seaweed basic ecological strategy in ensuring continued survival, growth, and reproduction is reflected by how effective they balance and allocate limited resources obtained by photosynthesis, such as from blades, stems and receptacles [44]. In the maturation period, the growth in receptacle biomass was the highest of the various organs, and the blade and stem biomass tended to increase at a similar rate, which shows that the seaweed allocated more energy to reproductive organs and, thus, reduced the energy allocation to other vegetative organs. This was consistent with the findings of Yan Xiaohong, in which the proportion of flower biomass in Bidens frondosa was found to increase rapidly during reproduction, in line with the hypothesis of optimal energy allocation $[3,38,45]$. In the maturation period of Sargassum fusiforme, there were different trends in biomass partitioning based on resource allocation according to different heights. Our analysis showed that with 
the increase in macroalgae height, the proportion of blade and stem biomass decreased gradually, and the rate of biomass reduction was greater in blades than in stems. The proportion of receptacle biomass increased gradually with the increase in plant height. This also reflected the rule of individual size dependence in resource allocation during the growth of Sargassum fusiforme. The larger macroalgae allocate more resources and invest more in the reproductive parts. It may also be that macroalgae with a larger plant height are greatly affected by waves, and that the surface area of blades is larger than that of branches and receptacles. To adapt to the environment and reduce water flow damage to their body, macroalgae reduced the biomass distribution to blades, and there was a lot of mucus on the surface of receptacles, which had low water resistance. This research explored the allometric growth relationship of different organs in the maturation period of Sargassum fusiforme to provide a new reference for establishing more comprehensive biomass relationships under different growth conditions. The results provide a theoretical basis for the exploration of mechanisms underlying biomass allocation and the evaluation of seaweed resources.

Author Contributions: Conceptualization, X.L. and S.Z.; methodology, K.W. and X.L.; software (SPSS 25, 20 March 2021), X.L. and J.C.; validation, K.W. and X.L.; formal analysis, X.L. and K.W.; investigation, X.L. and J.C.; resources, S.Z.; data curation, X.L. and J.C.; writing-original draft preparation, X.L. and J.C.; writing-review and editing, X.L., S.Z. and K.W.; visualization, X.L. and S.Z.; supervision, S.Z.; project administration, K.W. and S.Z.; funding acquisition, S.Z. All authors have read and agreed to the published version of the manuscript.

Funding: This research was funded by China Agriculture Research System (CARS-50) and the open research foundation of the Key Laboratory of Marine Ecological Monitoring and Restoration Technologies (MEMRT202113).

Institutional Review Board Statement: Not applicable.

Informed Consent Statement: Not applicable.

Data Availability Statement: Not applicable.

Acknowledgments: We appreciate the support of our funding agency, the China Agriculture Research System (CARS-50), and the Key Laboratory of Marine Ecological Monitoring and Restoration Technologies (MEMRT202113). We would also like to thank the editor and the anonymous reviewers, whose comments significantly improved the manuscript.

Conflicts of Interest: The authors declare no conflict of interest.

\section{References}

1. Daryaii, L.B.; Samsampour, D.; Bagheri, A.; Sohrabipour, J. High content of heavy metals in seaweed species: A case study in the Persian Gulf and the Gulf of Oman in the southern coast of Iran. Phycol. Res. 2021, 4, 544-560.

2. Yahya, B.M.; Yahya, S.A.; Mmochi, A.J.; Jiddawi, N.S. The trophic structure of fish in seaweed farms, and adjacent seagrass and coral habitats in Zanzibar, Tanzania. West. Indian Ocean. J. Mar. Sci. 2021, 19, 17-27. [CrossRef]

3. Yan, X.H.; He, C.L.; Zou, B.; Wang, N. Biomass Distribution and Allometric Analysis of Bidens frondosa Relative to Growth Stage. J. Ecol. Rural Environ. 2017, 33, 150-158.

4. Liu, Q.J. Nested regression for establishing tree biomass equations. Chin. J. Plant Ecol. 2009, 33, 331-337.

5. Akpalu, L.A.; Barnes, V.R.; Segbefia, A.Y. Assessment of Fishers' Knowledge and Willingness to Adopt Seaweed Cultivation in Ghana in Relation to Gender, Age, Education, and Distance. Int. J. Appl. Geospat. Res. 2021, 12, 47-65. [CrossRef]

6. Bell, T.W.; Allen, J.G.; Cavanaugh, K.C.; Siegel, D.A. Three decades of variability in California's giant kelp forests from the Landsat satellites. Remote Sens. Environ. 2020, 238, 110811. [CrossRef]

7. Wilson, K.L.; Skinner, M.A.; Lotze, H.K. Eelgrass (Zostera marina) and benthic habitat mapping in Atlantic Canada using high-resolution SPOT 6/7 satellite imagery. Estuar. Coastal Shelf Sci. 2019, 226, 106292. [CrossRef]

8. Cao, J.J.; Leng, W.C.; Liu, K.; Liu, L.; Zhu, Y.H. Object-based mangrove species classification using unmanned aerial vehicle hyperspectral images and digital surface models. Remote Sens. 2018, 10, 89. [CrossRef]

9. Kattenborn, T.; Eichel, J.; Fassnacht, F.E. Convolutional Neural Networks enable efficient, accurate and fine-grained segmentation of plant species and communities from high-resolution UAV imagery. Sci. Rep. 2019, 9, 17656. [CrossRef]

10. Fan, G.H.; Cui, Z.; Zhang, J.W.; Huang, Y.X.; Shen, X.J.; Zhao, X.Y. Effects of population density on the biomass allocation and allometric growth of Chenopodium acuminatum. Acta Ecol. Sin. 2017, 37, 5080-5090. 
11. McConnaughay, K.D.M.; Coleman, J.S. Biomass allocation in plants: Ontogeny or optimality? A test along three resource gradients. Ecology 1999, 80, 2581-2593. [CrossRef]

12. Lan, J.; Xiao, Z.Q.; Li, J.Z.; Zhang, Y.T. Biomass allocation and allometric growth of Picea schrenkiana in Tianshan Mountains. J. Zhejiang A F Univ. 2020, 37, 416-423.

13. Liu, T.; Shang, H.L.; Luo, J.; Sun, S.Q.; He, Y.M.; Li, A.D.; Zhang, J. Allometric Equations for Four Common Tree Species in Retreated Area of Hailuogou Glacier, Gongga Mountain. Southwest China J. Agric. Sci. 2019, 32, 922-928.

14. Segura, M.; Kanninen, M. Allometric models for tree volume and total aboveground biomass in a tropical humid forest in Costa Rica. Biotropica 2005, 37, 2-8. [CrossRef]

15. Lim, H.; Lee, K.; Lee, K.H.; Park, I.H. Biomass Expansion Factors and Allometric Equations in an Age Sequence for Japanese Cedar (Cryptomeria japonica) in Southern Korea. J. For. Res. 2013, 18, 316-322. [CrossRef]

16. Sattar, A.; Sher, A.; Ijaz, M.; Ullah, M.S.; Umar, U.D. Individual and combined effect of terminal drought and heat stress on allometric growth, grain yield and quality of bread wheat. Pak. J. Bot. 2020, 52, 405-412. [CrossRef]

17. Zhu, J.; Han, H.R.; Kang, F.F.; Cheng, X.Q.; Wang, T.; Wang, L.X.; Tian, P. Biomass allocation patterns and allometric models of Larix principisrupprechtii in Mt. Taiyue, Shanxi. Chin. J. Ecol. 2016, 35, 2918-2925.

18. Heineman, K.D.; Jensen, E.; Shapland, A.; Bogenrief, B.; Tan, S.; Rebarber, R.; Russo, S.E. The effects of belowground resources on aboveground allometric growth in Bornean tree species. For. Ecol. Manag. 2011, 261, 1820-1832. [CrossRef]

19. Niklas, K.J. A phyletic perspective on the allometry of plant biomass-partitioning patterns and functionally equivalent organcategories. New Phytol. 2006, 171, 27-40. [CrossRef]

20. Santos, R. Size structure and inequality in a commercial stand of the seaweed Gelidium sesquipedale. Mar. Ecol. Prog. Ser. 1995, 119, 253-263. [CrossRef]

21. Stagnol, D.; Macé, M.; Destombe, C.; Davoult, D. Allometric relationships for intertidal macroalgae species of commercial interest. J. Appl. Phycol. 2016, 28, 3407-3411. [CrossRef]

22. Liu, L.J.; Lin, L.D. The effect of high temperature on stress physiology of Sargassum fusiforme. J. Trop. Oceanogr. 2021, 40, 74-82.

23. Ruan, J.H.; Xu, L.G. A preliminary study on the reproductive and developmental biology of Sargassum fusiforme (Harvs) Setch. J. Zhejiang Univ. 2001, 28, 315-320.

24. Zhang, Z.; Liu, J.G.; Liu, J.D. Study review of Hizikia fusiformis. Mar. Fish. Res. 2002, 23, 67-74.

25. Li, X.M.; Zhang, S.Y.; Wang, K.; Chen, L.R.; Chen, T.H. Effect of annual temperature variation on growth of Sargassum horneri in GouqI Island. Oceanolgia Limnol. Sin. 2020, 51, 1136-1143.

26. Zhang, S.Y.; Xiang, C.; Zhou, X.J.; Liu, S.R.; Cheng, X.P.; Wang, K. Photosynthetic fluorescence characteristics of six macroalgae species in seaweed beds of Gouqi Island, Zhejiang, China. Chin. J. Appl. Ecol. 2018, 29, 3441-3448.

27. Zeng, C.K. Flora Economic Algarum Marinarum Sinicarum (Book3 Phaeophyta Volume 2); Science Press: Beijing, China, $1962 ;$ p. 32.

28. Chen, L.R.; Zhang, S.Y.; Chen, Y.; Zhao, X.; Zhou, X.J.; Chen, Y.Z. Life history and morphology of Sargassum horneri from the Sargassum seaweed bed of Gouqi Island. J. Fish. China 2015, 39, 1218-1229.

29. Díaz-Villa, T.; Sansón, M.; Afonso-Carrillo, J. Seasonal variations in growth and reproduction of Sargassum orotavicum (Fucales, Phaeophyceae) from the Canary Islands. Bot. Mar. 2005, 48, 18-29. [CrossRef]

30. Vinh, T.V.; Marchand, C.; Linh, T.V.K.; Vinh, D.D.; Allenbach, M. Allometric models to estimate above-ground biomass and carbon stocks in Rhizophora apiculata tropical managed mangrove forests (Southern Vietnam). For. Ecol. Manag. 2019, 434, 131-141. [CrossRef]

31. Li, L.; Li, Y.; Ma, Q.; Yu, H.; Xu, Z. Aboveground biomass modeling and allometric growth characteristics of Artemisia capillaris Thunb. under different water availabilities. Chin. J. Ecol. 2020, 39, 337-348.

32. Falster, D.S.; Warton, D.I.; Wright, I.J. User's Guide to SMATR: Standardised Major Axis Tests \& Routines Version 2.0. 2006. Available online: http//:www.bio.mq.edu.au/cology/SMATR/ (accessed on 20 November 2020).

33. Warton, D.I.; Wright, I.J.; Falster, D.S.; Westoby, M. Bivariate line-fitting methods for allometry. Biol. Rev. 2006, 81, 259-291. [CrossRef]

34. Niklas, K.J. Modelling Below-and Above-ground Biomass for Non-woody and Woody Plants. Ann. Bot. 2005, 95, 315-321. [CrossRef] [PubMed]

35. Liu, Z.W.; Chen, R.S.; Song, Y.X.; Han, C.T. Distribution and estimation of aboveground biomass of alpine shrubs along an altitudinal gradient in a small watershed of the Qilian Mountains, China. J. Mt. Sci. 2015, 12, 961-971. [CrossRef]

36. Ma, S.X.; Ding, H.H.; Liu, H.D.; Zhu, J.L.; Yin, S.Y.; Zhang, X.X.; Yang, S.T.; Sun, Z.Q. Biomass model of Eucommia ulmoides Oliver short rotation coppice. J. Fujian Agric. For. Univ. 2018, 47, 681-685.

37. Bai, Z.Q.; Li, Y.; Wang, W.D.; Liu, R.; Han, Y.L.; Liu, H. Biomass Model Establishment and Allocation of Dominant Tree Species in Altai Mountains. For. Resour. Manag. 2018, 4, 34-40.

38. Shipley, B.; Meziane, D. The balanced-growth hypothesis and the allometry of leaf and root biomass allocation. Funct. Ecol. 2010 16, 326-331. [CrossRef]

39. Li, S.X.; Ye, D.S.; Guo, W.L.; Sun, J.Z. Investigation and prevention of harmful organisms for the cultivation of Sargassum fusiforme (Harv.) Okam. Mod. Fish. Inf. 2009, 24, 19-22.

40. Zhao, S.F. Marine Algae and Algal Culture Science; National Defense Industry Press: Beijing, China, 2012.

41. Meng, W.J.; Wang, P.; Gui, F.K.; Wu, C.W.; Liang, J. Nutrient uptakes by Inshige foliaceaokamurai and Sargassum fusiforme differ in algal section and mass, Carbon concentration, and water flow. Oceanolgia Limnol. Sin. 2014, 45, 663-668. 
42. Schlichting, C.D.; Smith, H. Phenotypic Plasticity: Linking Molecular Mechanisms with Evolutionary Outcomes. Evol. Ecol. 2002, 16, 189-211. [CrossRef]

43. Weiner, J. Allocation, Plasticity and Allometry in Plants. Perspect. Plant Ecol. 2004, 6, 207-215. [CrossRef]

44. Feng, L.; Zhang, J.G.; Zhang, Z.S.; Guo, Q.; Li, X.R. Growth and biomass allocation dynamics of Artemisia ordosica in sand-fixing vegetation of the Tengger Desert of China. Chin. J. Plant Ecol. 2009, 33, 1132-1139.

45. McCarthy, M.C.; Enquist, B.J. Consistency between an allometric approach and optimal partitioning theory in global patterns of plant biomass allocation. Funct. Ecol. 2007, 21, 713-720. [CrossRef] 